\title{
LA-UR-96- 3183
}

$$
\begin{array}{ll} 
& \text { RECEIVED } \\
\text { Author(s): } & \begin{array}{l} 
\\
\text { D.e. Daney, ESA-EPE } \\
\text { H.J. Boenig, DX-6 } \\
\text { M.P. Maley, STC }
\end{array} \\
\text { D.E. McMurry, MST-11 } & \text { SEP 23 } \\
\text { B.G. DeBlanc, STC } &
\end{array}
$$

\section{RECEIVED \\ SEP 231989 \\ OSTI}

Submitted to:

Applied Superconductivity Conference

Pittsburgh, PA

August 26-30, 1996

DISTRIBUTION OF THIS DOCUMENT IS UNLIMITES

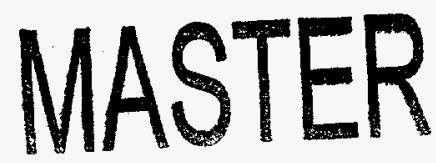

\section{Los Alamos}

NATIONAL LABORATORY

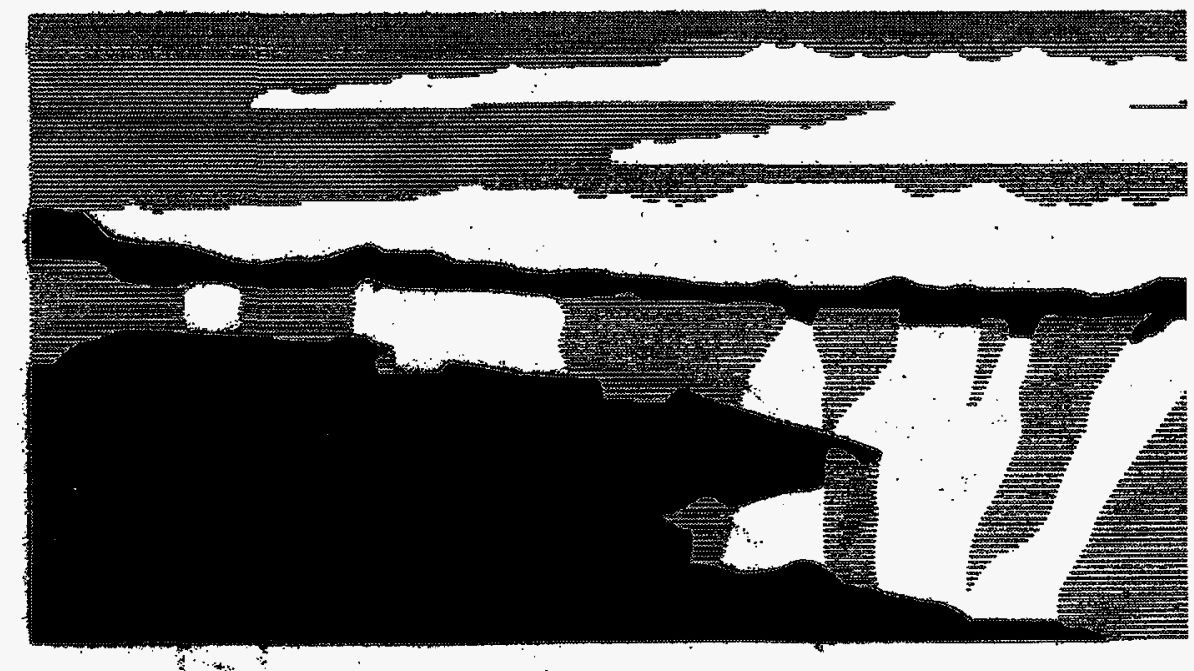

Los Alamos National Laboratory, an affirmative action/equal opportunity employer, is operated by the University of California for the U.S, Department of Energy under contract W-7405-ENG-36. By acceptance of this article, the publisher recognizes that the U.S. Government retains a nonexclusive, royalty-free license to publish or reproduce the published form of this contribution, or to allow others to do so, for U.S. Government purposes. The Los Alamos National Laboratory requests that the publisher identify this article as work performed under the auspices of the U.S. Department of Energy. 


\section{DISCLAIMER}

Portions of this document may be illegible in electronic image products. Images are produced from the best available original document. 


\section{DISCLAIMER}

This report was prepared as an account of work sponsored by an agency of the United States Government. Neither the United States Government nor any agency thereof, nor any of their employees, makes any warranty, express or implied, or assumes any legal liability or responsibility for the accuracy, completeness, or usefulness of any information, apparatus, product, or process disclosed, or represents that its use would not infringe privately owned rights. Reference herein to any specific commercial product, process, or service by trade name, trademark, manufacturer, or otherwise does not necessarily constitute or imply its endorsement, recommendation, or favoring by the United States Government or any agency thereof. The views and opinions of authors expressed herein do not necessarily state or reflect those of the United States Government or any agency thereof. 


\title{
Ac Loss Calorimeter for Three-Phase Cable
}

\author{
D. E. Daney, H. J. Boenig, M. P. Maley, D. E. McMurry, and B. G. DeBlanc \\ Superconductivity Technology Center, Los Alamos National Laboratory, Los Alamos, NM 87545
}

\begin{abstract}
A calorimeter for measuring ac losses in meter-long lengths of HTS superconducting power transmission line cables is described. The calorimeter, which is based on a temperature difference technique, has a precision of $1 \mathrm{~mW}$ and measures single, two-phase (conpling), and three-phase losses. Our measurements show significant coupling losses between phases.
\end{abstract}

\section{INTRODUCTION}

We describe the theory and design of, and preliminary measurements from, a calorimeter for measuring three-phase ac losses of high temperature superconducting (HTS) cables for power transmission lines (SPTL). The calorimeter is part of a joint HTS-SPTL program involving Pirelli Cavi S.p.A., American Superconductor Corporation, the Electric Power Research Institute, and the Superconductivity Technology Center (STC) of Los Alamos National Laboratory.

The design goals for the full-scale cable are $2000 \mathrm{~A} \mathrm{rms}$ nominal current with ac losses of $1 \mathrm{~W} / \mathrm{m}$ or less per phase. For initial test purposes, however, we are studying losses in a prototype multi-strand conductor (PMC) with reduced current capacity to aid in the design of a full-scale cable. The PMC used in the initial series of measurements is one meter long and composed of two helically-wound, non-insulated layers of HTS tape (19 tapes per layer) wrapped on a 28.6$\mathrm{mm}$ diameter G-10 glass-epoxy mandrel. The 2 layers are wrapped with opposite pitch, so that the net azimuthal component of current in the cable is zero. The tapes are soldered to copper end connectors.

We chose a calorimetric technique for measuring the ac losses in PMCs because electrical measurement techniques give widely varying results, which depend largely on the technique used, even for single superconducting tapes ${ }^{1}$. For multistrand, helically wound cables that experience ac magnetic fields from the other two phases of a 3-phase transmission line, electrical measurement difficulties would be even more severe because of induced circulating currents that do not produce a coherent voltage drop along the sections of tape conductors.

Manuscript received August 27, 1996

this work was performed under the auspices of the US Department of Energy, Office of Energy Management and, the Electric Power Research Institute
Because we believe there are difficulties (cable porosity and axial conduction) in measuring electrical losses by using standard boil-off calorimetry, we have devised an alternative calorimetric technique for measuring electrical losses in meter-long lengths of cable that we call temperature-difference calorimetry. This technique allows accurate loss measurement because cable end effects do not influence the measurement. The precision of the calorimeter is better than $1 \mathrm{~mW}$.

\section{THEORY OF TEMPERATURE-DIFFERENCE CALORIMETRY}

The operating principle of the temperature-difference calorimeter is the parabolic temperature distribution that develops in a rod or cable with uniform internal heat generation (electrical losses), that is vacuum insulated on its periphery and cooled at each end. The solution to the steady-state heat conduction equation with internal heat generation,

is then

$$
\frac{\mathrm{d}^{2} \mathrm{~T}}{\mathrm{dx}^{2}}=-\frac{\mathrm{qL}_{\mathrm{L}}}{\mathrm{kA}},
$$

$T-\frac{1}{2}\left(T_{0}+T_{L}\right)=-\frac{q_{L}}{2 k A}\left[\left(\frac{L}{2}\right)^{2}-x^{2}\right]+\left(T_{L}-T_{0}\right) \frac{x}{L}$

for the asymmetrical boundary conditions, $T=T_{0}$ at $x=-L / 2$ and $T=T_{L}$ at $x=+L / 2$, which occur in practice due to small asymmetries in contact resistances and heat transfer. Here $T$ is the cable temperature at axial position $x, q_{L}$ is the heat generation (loss) per unit length, $\mathrm{k}$ is the effective thermal conductivity of the cable, $A$ is the cable cross-sectional area, and $\mathrm{L}$ is the cable length.

The cable and calorimeter are calibrated in situ using a heater wound around the cable midpoint to determine the effective value of the thermal conductance, $\mathrm{kA}$, which from the conduction equation is

$$
(\mathrm{kA})_{\text {effective }}=-\frac{1}{2} \frac{\mathrm{Q}_{\mathrm{c}}}{(\mathrm{dT} / \mathrm{dx})_{\mathrm{c}}}
$$

where $(\mathrm{dT} / \mathrm{dx})_{\mathrm{c}}$ is the average of the measured linear temperature gradients for each half of the cable produced by the applied heater power $\mathrm{Q}_{\mathrm{c}}$. The factor $1 / 2$ occurs because the calibration heater power is split between the two halves of the cable. Combining eqns. (2) and (3) gives the governing equation for the temperature difference calorimeter:

$$
\mathrm{q}_{\mathrm{L}}=-4 \frac{\mathrm{Q}_{\mathrm{C}}\left(\overline{\mathrm{T}_{\mathrm{m}}-1 / 2\left(\mathrm{~T}_{0}-\mathrm{T}_{\mathrm{L}}\right)}\right)}{(\mathrm{dT} / \mathrm{dx})_{\mathrm{c}}}
$$


with the difference between the centerline and end temperatures determined from a curve fit to the temperatures of thermometers positioned axially and azimuthally on the cable, and $\mathrm{L}$ being the axial distance between the thermometers placed near the ends of the cable.

Two advantages of our technique are:

1) the measurement is not affected by axial conduction into the test section, and

2) end effects are eliminated since (4) applies to any section of cable symmetric about the axial mid-point.

Because heat flows away from the measurement section, end losses raise the overall temperature level of the cable somewhat, but they do not affect the temperature between the mid-point and the ends.

Because the resistance between the HTS tapes and the end fittings is a significant fraction of the total electrical resistance for the one-meter PMC, variations in resistance from joint to joint cause a similar variation in the current carried by each tape. The resulting variations in losses, and hence in temperature rise, between tapes are a source of error in the loss measurement, since (4) assumes a homogeneous cable with uniform heating. By measuring the cable temperature at several azimuthal positions for each axial position, we obtain a better estimate of the average temperature rise at each axial position. The azimuthal temperature variation provides an estimate of the non-uniformity of the current. Thermal and electrical contact between the tapes help balance the current among the tapes, as well as help reduce azimuthal temperature variations. We observe no significant azimuthal variation for PMC \#1.

\section{CALORIMETER DESIGN}

The calorimeter, Fig. 1, is made largely from G-10 glassepoxy composite making it transparent to electromagnetic fields. This design allows the PMC to see each of the other two phases of the three-phase (only two phases shown in side view) configuration. Thus coupling losses between phases are included in the total loss measured.

The PMC superconducting cable (lower center of Fig. 1) is enclosed by an insulating vacuum formed by a $98-\mathrm{mm}$ id. G-10 tube with stainless steel end flanges. A stainless-steel bellows on the right hand side of the cable enclosure accommodates differential axial contraction between the cable and the enclosure, and angular misalignment of the PMC end fitting bolt holes. The end flanges of the PMC enclosure are sealed with a $1.6 \mathrm{~mm}$ thick GORE-TEX ${ }^{\mathrm{TM}}$ gaskets compressed to over $21 \mathrm{MPa}$. This joint allows a vacuum of $10^{-2}$ $\mathrm{Pa}$ in the PMC enclosure.

The PMC enclosure, together with the two normal conductors, is immersed in a bath of liquid nitrogen, which can be varied in temperature from $64 \mathrm{~K}$ to $80 \mathrm{~K}$ by control of the bath pressure. The conductor spacing $(10 \mathrm{~cm}$ nominal) between phases is established by G-10 plates bolted to each end of the PMC enclosure. This spacing can be varied from 7 to $20 \mathrm{~cm}$. Both normal conductors are made from $31.8-\mathrm{mm}$ diameter ETP copper rods, each of which dissipates $3.6 \mathrm{~W}$ with 1200 A current.

The LN2 vessel, with an i.d. of $302 \mathrm{~mm}$, is made of 304 stainless steel. The end plate seals are GORE-TEX ${ }^{\mathrm{TM}}$ gaskets similar to the ones used on the PMC enclosure. A pair of perforated, annular segments of G-10 support the LN2 vessel from the base of the vacuum vessel that provides thermal insulation for the calorimeter. Because the total estimated heat leak down the current leads is $300 \mathrm{~W}$, compared to only a few watts through the thermal insulation, only modest attention to thermal insulation of the LN2 vessel is justified.

\section{A. Calorimeter}

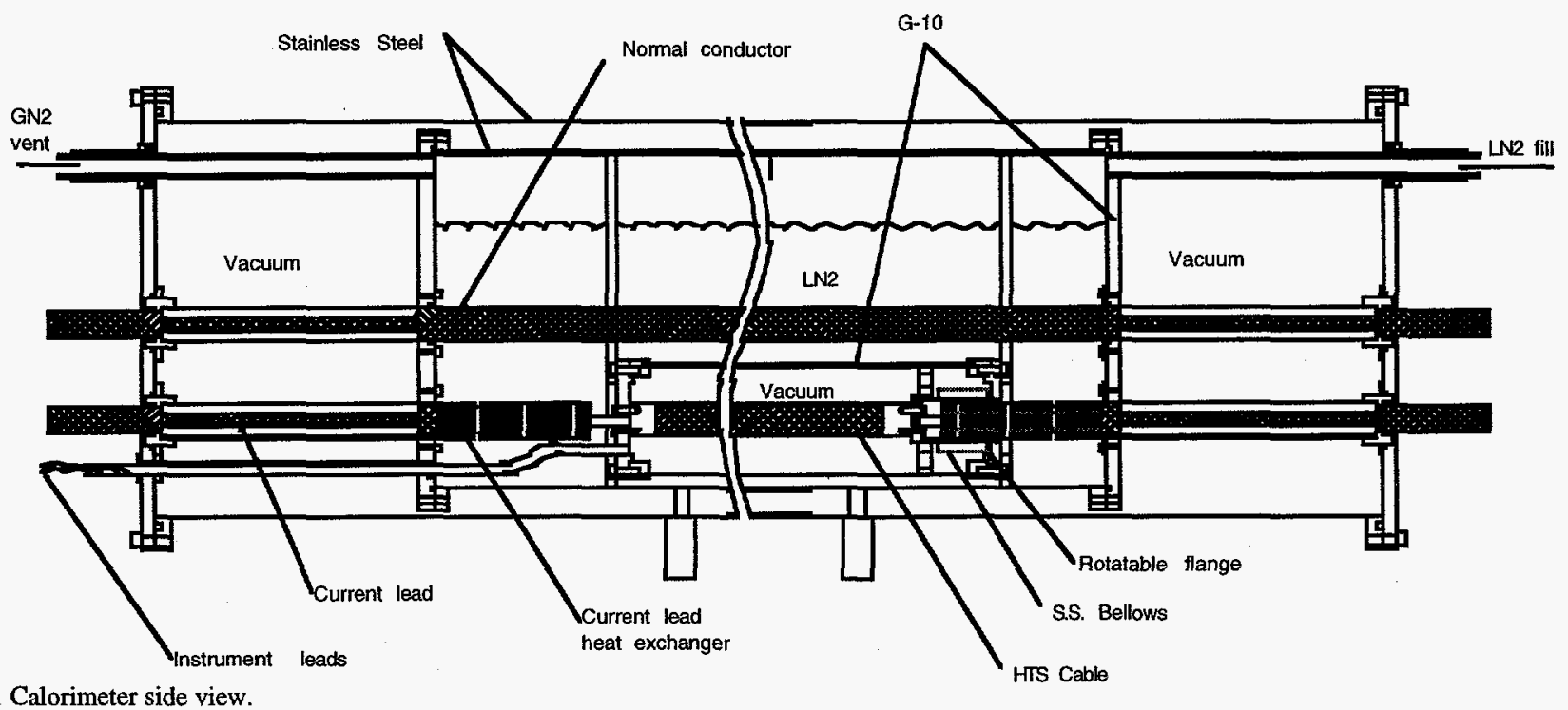

Fig. 1 Calorimeter side view. 


\section{B. Current Leads}

The current leads extend from each end of the calorimeter. With this double-ended design we can easily configure the return-end circuit to give single-phase, two-phase (no current through the PMC) or three-phase without having to warm-up the calorimeter. We selected conduction-cooled current leads rather than gas-cooled leads. This choice simplifies the calorimeter design by allowing the leads to penetrate the vessels horizontally, thus confining differential thermal contraction problems to the horizontal axis. An additional advantage of this configuration is that EMF end effects on the PMC are virtually eliminated since the leads and cable lie on the same axis. Unlike current leads for helium temperature devices, losses in current leads for nitrogen temperature devices are only a little higher for conduction-cooled leads than for gas-cooled leads ${ }^{2}$.

\section{AC Power Supply}

The calorimeter is powered by a variable ac, $60 \mathrm{~Hz}$, three-phase current source with continuously adjustable current values from zero to $2500 \mathrm{rms}$. To obtain continuously adjustable currents with as few harmonics as possible, a conventional design for the power supply was chosen with a series connection of a three -phase, variable voltage transformer and a step-down transformer, as shown in Fig. 2 . The current rating of the secondary winding is $2500 \mathrm{~A}$. The circuit connection for the transformer is delta/wye and the secondary no load voltage is $3 \mathrm{~V}$. To obtain good controllability of the current in the superconducting cable a high short circuit impedance of 12 to $15 \%$ was chosen for the transformer. The transformer, which has a power rating of $21.6 \mathrm{kVA}$, is custom built with a low flux density in the iron to avoid any saturation, which would result in harmonic currents with a frequency of $180 \mathrm{~Hz}$.

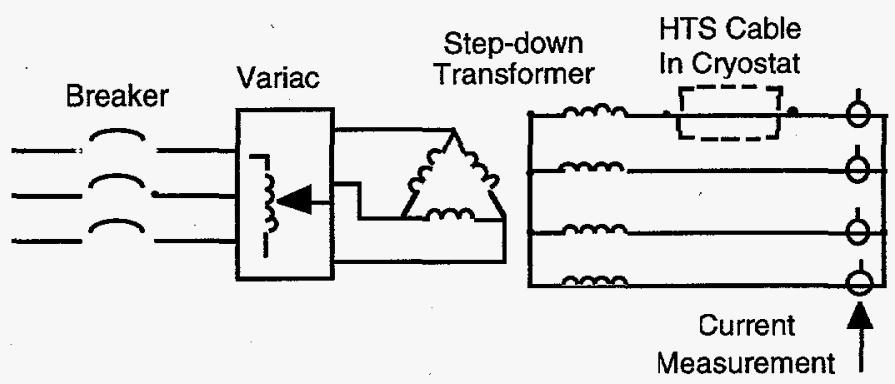

Fig. 2 Electrical circuit for calorimeter

\section{INSTRUMENTATION AND DATA ACQUISITION}

We selected miniature platinum resistance thermometers (1.8- $\mathrm{mm}$ in diameter by $5-\mathrm{mm}$ long) to measure the PMC temperatures. We achieve a precision (random error) of $0.001 \mathrm{~K}$ in the measurement of the temperature rise equivalent to a precision of $1 \mathrm{~mW}$ in the a.c. loss. Fourteen thermometers are positioned symmetrically about the
PMC at six axial locations so as to detect non-uniformities in the heat generated. By attaching the thermometers at the seams between tapes, we double the number of tapes sampled. To eliminate the effects of ac pickup of the cable fields by the thermometry, we read the thermometers immediately after the power is cut from the cables, as well as while current is flowing. To our surprise, the effects of current flow on the loss measurement is negligible.

Data are collected with a Macintosh computer using LabVIEW $^{\mathrm{TM}}$ software to control the interface with the instruments. The thermometers are interrogated by an HP $3794 \mathrm{~A}$ integrating voltmeter/multiplexer which has a precision of $\pm 0.5 \mu \mathrm{V}$. All 14 thermometers can thus be interrogated within $2 \mathrm{~s}$.

\section{EXPERIMENTAL RESULTS}

Fig. 3 illustrates the parabolic temperature profile that develops in the cable due to the ac losses. Measurements for all 14 thermometers are plotted. The near coincidence of the measurements (three each) at the four interior positions indicates that there is little azimuthal variation in the loss, and by inference in the current.

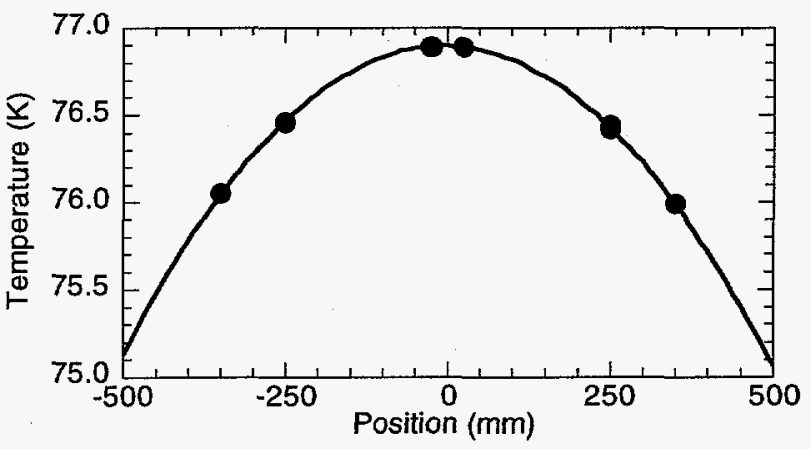

Fig. 3. Typical parabolic temperature profile in the PMC. Conditions are: 800 Arms single-phase with $75 \mathrm{~K}$ bath

Fig. 4 shows the response of the PMC midpoint temperature to the application of ac current. The 1/e time constant is about 12 minutes, so about an hour is required to approach steady state to closer than one percent.

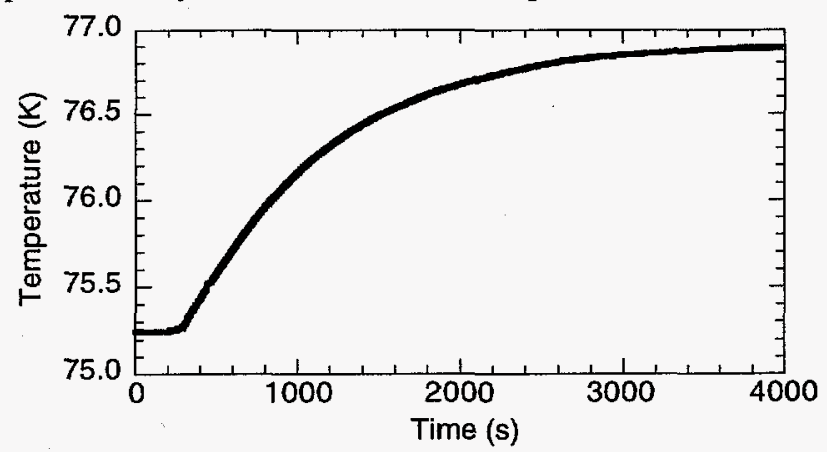

Fig. 4. Typical approach of cable midpoint to steady state following application of a current of 800 Arms. 
Figure 5 summarizes our ac loss measurements on PMC \#1 at a bath temperature of $75.2 \mathrm{~K}$. With single-phase operation the return current path is outside the calorimeter about one meter away. With two-phase operation current flows through the two normal conductors and the PMC is disconnected. Thus the two-phase losses are induced by coupling only since there is zero net current in the PMC. With three-phase operation current flows in all three phases (centers located at the corners of an equilateral triangle with $10 \mathrm{~cm}$ sides). The losses are corrected to the $75.25 \mathrm{~K}$ bath temperature using the measured loss temperature dependence shown in Fig. 6.

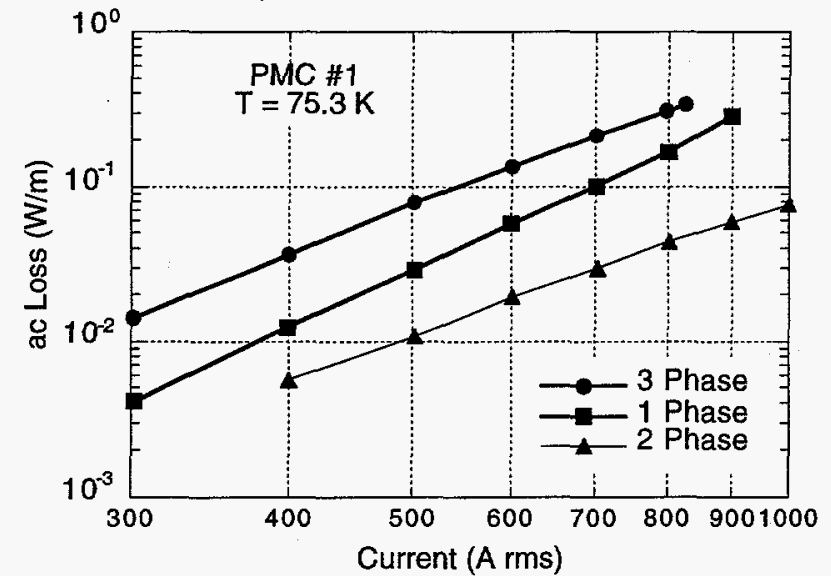

Fig. 5. Measured ac loss for PMC \#1. Losses are corrected to $75.25 \mathrm{~K}$ using Fig. 6.

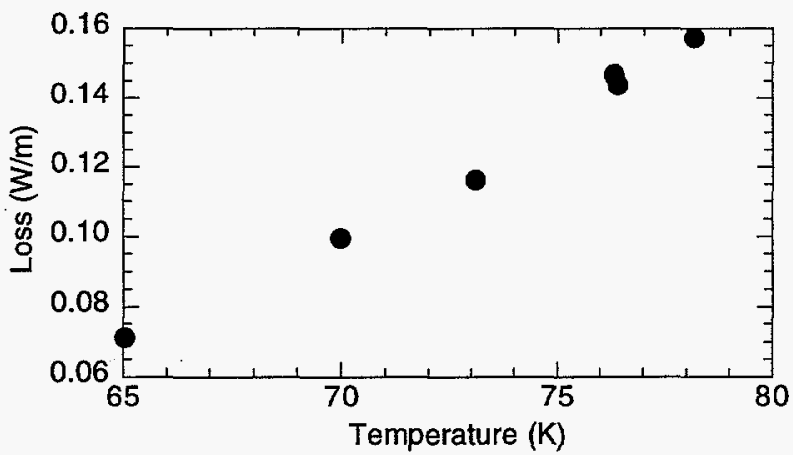

Fig. 6. Measured temperature dependence of three-phase ac losses at 600 Arms.

\section{DISCUSSION}

As shown in Fig. 5, the losses in all configurations follow a power law, $P_{L} \propto \mu I_{0}{ }^{n}$ over most of the current range, where $I_{0}$ is the current amplitude and $3<n<4$. An upward deviation from power law behavior is observed at current levels above $900 \mathrm{~A} \mathrm{rms}$, which corresponds closely with the measured dc critical current for the PMC. It is interesting that the losses measured in the 2-phase mode, corresponding to losses coming from currents induced in the PMC by the AC fields coming from the other 2 phases, are easily observable. Moreover, the 3-phase losses are roughly twice the single phase losses and are clearly larger than the sum of the single and 2-phase loss curves. This non-linear effect in the interaction of an ac transport current with an imposed transverse ac field is generally referred to as "dynamic resistance" 3 . We intend to further investigate the relation between losses in these 3 configurations for the double-helix cable configuration. The magnitude of the losses in the single phase mode are in rough agreement with the Bean-model prediction ( $\mathrm{PL}_{\mathrm{L}}=\mu_{\mathrm{o}} f \mathrm{I}_{o} \mathrm{n} / 6 \pi \mathrm{I}_{\mathrm{C}} \mathrm{W} / \mathrm{m}$ ) for a round conductor of the same radius. Here $f$ is the frequency, $n=3$, and $I_{\mathcal{C}}$ is the critical current of the solid cylindrical conductor with the same engineering $J_{c}$ as the double-helix PMC, in the partially penetrated condition. The dependence of losses on the inverse of the critical current is further corroborated by the data in figure 6 , which shows the losses at a fixed current amplitude as a function of temperature. The roughly factor of 2 decrease of the losses between $78 \mathrm{~K}$ and $65 \mathrm{~K}$ is in good agreement with the measured increase of the critical current of the tapes used in the PMC over this same range. Studies of PMCs incorporating interlayer insulation are planned for the near future.

\section{ACKNOWLEDGMENTS}

We would like to acknowledge the contributions of Steven Fleshler and American Superconductor Corp. in fabricating the PMC and for useful discussions, and to Paul Grant of EPRI for support and encouragement.

\section{REFERENCES}

[1] S. Fleshler, L.T. Cronis, G.E. Conway, A.P. Malozemoff, J. Mc Donald, T. Pe, J.R. Clem. G. Vellego, and P. Metra, "Measurement of the true a.c power loss of $\mathrm{Bi}-2223$ composite tape using the transparent technique", to be published in Applied Physics Letters.

[2] P.F. Herrmann, C. Cottevieille, G. Duperray, A. Leriche, T. Verhaege, C. Albrecht, and J. Boch, "Cryogenic load calculation of high $\mathrm{T}_{c}$ current lead", Cryogenics (1993) 33555 - 562

[3] J.H. Murphy and M.S. Walker, "Combined transport current and transverse field losses in multifilament superconductors", $A d$ vances in Cryogenic Engineering Vol. 24, 406 (1978). 